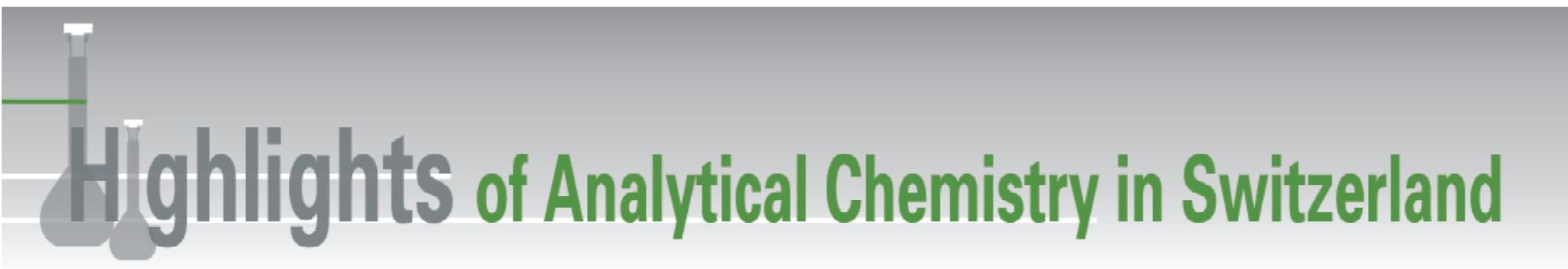

\section{An Environmental Case History of Platinum}

Urs Krähenbühª ${ }^{\star a}$ Céline Fragnière ${ }^{a, b}$, and Max Haldimann ${ }^{b}$

${ }^{*}$ Correspondence: Prof. Dr. U. Krähenbühla, ${ }^{a}$ Department of Chemistry and Biochemistry, University of Bern, Freiestrasse 3, CH-3012 Bern, Tel.: +413163142 65, Fax: +413163142 20, E-Mail: urs.kraehenbuehl@iac.unibe.ch

bSwiss Federal Office of Public Health, $\mathrm{CH}-3003$ Bern

Keywords: Car emissions - Catalytic converter · Peat bog · Platinum Group Elements · Platinum in the environment

In recent years, the air quality in the vicinity of motorways has improved due to the distinct reduction of hazardous car emissions such as VOC, $\mathrm{CO}$, and $\mathrm{NO}_{\mathrm{x}}$ thanks to the introduction of exhaust catalytic converters. They effect combined oxidation and reduction reactions in the presence of platinum group elements (PGE).

The first generation of catalytic converters contained Pt and $\mathrm{Rh}$ as active compounds. In the latest generations a large fraction of Pt has been replaced by the more abundant Pd. A combination of several PGEs is needed for the optimum decrease of noxious car emissions. The operation of any car equipped with a catalytic converter results in nano-gram quantities of PGEs being lost to the environment for each kilometer driven. So, PGEs may accumulate near streets and highways. Our research is focused on Pt emissions.

Peat cores were collected from Guin/Düdingen near the national highway A12 and from St Moritz, a remote area secluded from the Swiss midlands. Individual layers of the peat material were dated, digested, and analyzed for Pt using a Finnigan sector field ICP-MS. For the interference-free measurement of Pt a very dry aerosol is needed. Otherwise $\mathrm{HfO}^{+}$is formed, which overlaps the platinum

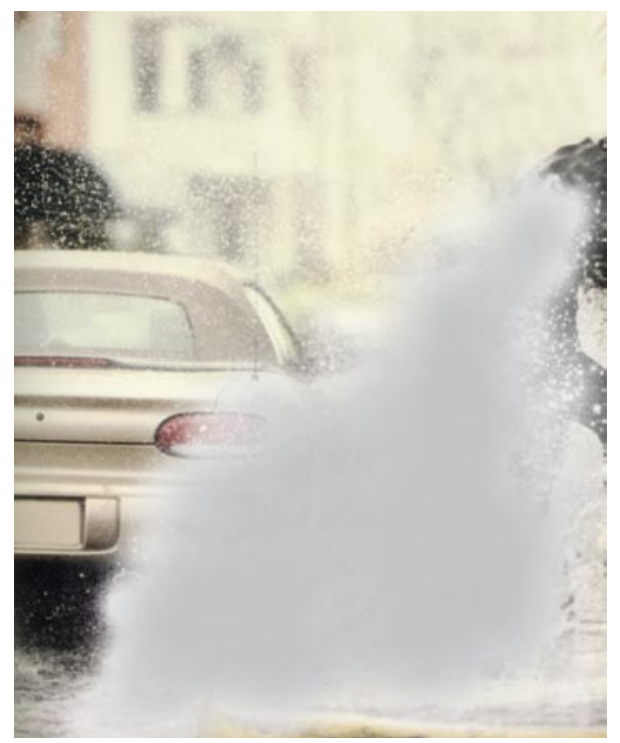

Cars are now equipped with exhaust catalytic converters - but not all environmental problems are solved isotopes of analytical interest. An APEX drying system reduced the Hf oxide interference by three orders of magnitude.

From the presented results it is quite evident that the emissions are proportional to the amount of traffic on the nearby road.

There is no clear understanding of PGE behaviour in the environment. Further work will focus around the speciation of the PGE emissions, since their toxicity is strongly influenced by the chemical form. In the meantime, PGE concentrations in the environment will continue to increase as long as PGE-based catalysts will be in use.

Received: March 27, 2006

Reference

C. Fragnière, M. Haldimann, A. Eastgate, U. Krähenbühl, J. Anal. At. Spectrom. 2005, 20, 626.

\section{Reduction Catalyst \\ $\mathrm{NO}+\mathrm{CO} \rightarrow \mathrm{CO}_{2}+1 / 2 \mathrm{~N}_{2}$ \\ Coating $=\mathrm{Pt} \& \mathrm{Pd}$}

\section{Oxidation Catalyst \\ $\mathrm{H}_{\mathrm{x}} \mathrm{C}_{\mathrm{y}}+{ }_{\mathrm{z}} \mathrm{O}_{2} \rightarrow \mathrm{m} \mathrm{CO}_{2}+\mathrm{n} \mathrm{H}_{2} \mathrm{O}$ \\ $2 \mathrm{CO}+\mathrm{O}_{2} \rightarrow 2 \mathrm{CO}_{2}$ \\ Coating $=$ P† \& Rh}

Reaction schemes in catalytic converters

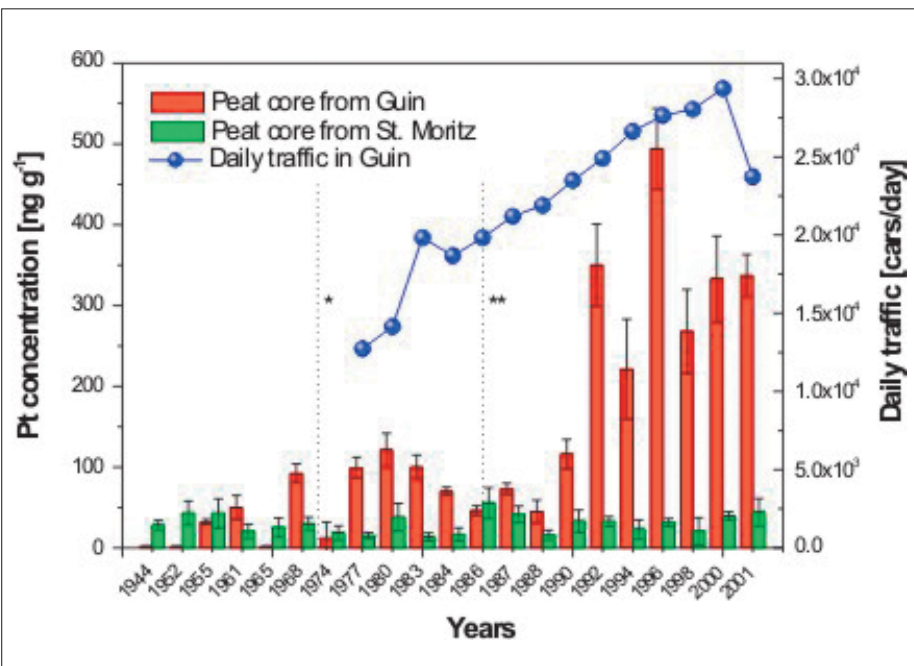

Peat bogs are ideal archives for unravelling the time dependent anthropogenic deposition of heavy metals. ${ }^{*}$ Start of construction of highway A12. ** Introduction of catalytic converters for cars. 